\title{
REABILITAÇÃo DA ANTIGA DELEGACIA DE POLÍCIA E CADEIA PÚBLICA DE ANGATUBA
}

\author{
Lígia Lisbôa Rodrigues
}

Arquitetura e Urbanismo, Planejamento Urbano, UNESP - Presidente Prudente. E-mail: Liginha03@hotmail.com

\section{RESUMO}

O presente trabalho apresenta uma proposta de reabilitação do antigo prédio da cadeia pública localizado na cidade de Angatuba, São Paulo. O prédio de estilo eclético, construído na década de 1920, possui valor histórico e cultural para a cidade, mas hoje se encontra em desuso, ao abandono. Após o trabalho de campo para estudo e diagnóstico da dinâmica da cidade, definiu-se que o novo uso terá um caráter cultural, uma vez que Angatuba possui potencial na realização de eventos culturais, porém há uma carência de espaço físico para tal. A proposta consiste na utilização do local para a implantação de um Espaço Múltiplo, onde pudessem ser realizados eventos culturais de diferentes tipos, suprindo as necessidades culturais da cidade de Angatuba e procurando reinserir a construção que foi excluída e perdeu significado no cotidiano da cidade contemporânea.

Palavras-chave: patrimônio histórico, reabilitação, restauração, espaço múltiplo, cultura .

\section{INTRODUÇÃO E OBJETIVO}

Angatuba é uma cidade do interior paulista com forte presença de prédios históricos, muitos deles abandonados, com risco de serem descaracterizados e até demolidos.

O antigo prédio da Delegacia de Policia e Cadeia Pública localiza-se nas proximidades do centro histórico, sendo de valor histórico, cultural e arquitetônico para a cidade. Devido às mudanças que a cidade passou ao longo dos anos, atualmente encontra-se em desuso, ao abandono.

O estudo sobre a reabilitação da cadeia não teve como objetivo trazer de volta sua antiga função, mas sim propor um novo uso que seja mais propício à contextualização da área.

\section{METODOLOGIA}

Para o desenvolvimento do presente trabalho, foi necessário o levantamento bibliográfico sobre o histórico da cidade e do prédio para compor o embasamento teórico, assim como um estudo sobre a temática do patrimônio histórico.

Foi feito, através do trabalho de campo, o levantamento de dados, imagens e notícias, para entender melhor as necessidades e particularidades do local.

A partir da análise destas informações, foi proposto a instalação de um Espaço Múltiplo, que dê suporte a diferentes atividades culturais. 


\section{RESULTADOS}

O antigo prédio de Delegacia de Polícia e Cadeia pública (FIGURA 1), encontra-se em desuso, uma vez que suas funções foram transferidas para um novo edifício de delegacia (FIGURA 2), construído à frente. No entanto, a antiga cadeia é um patrimônio histórico e arquitetônico de grande valor para a cidade.

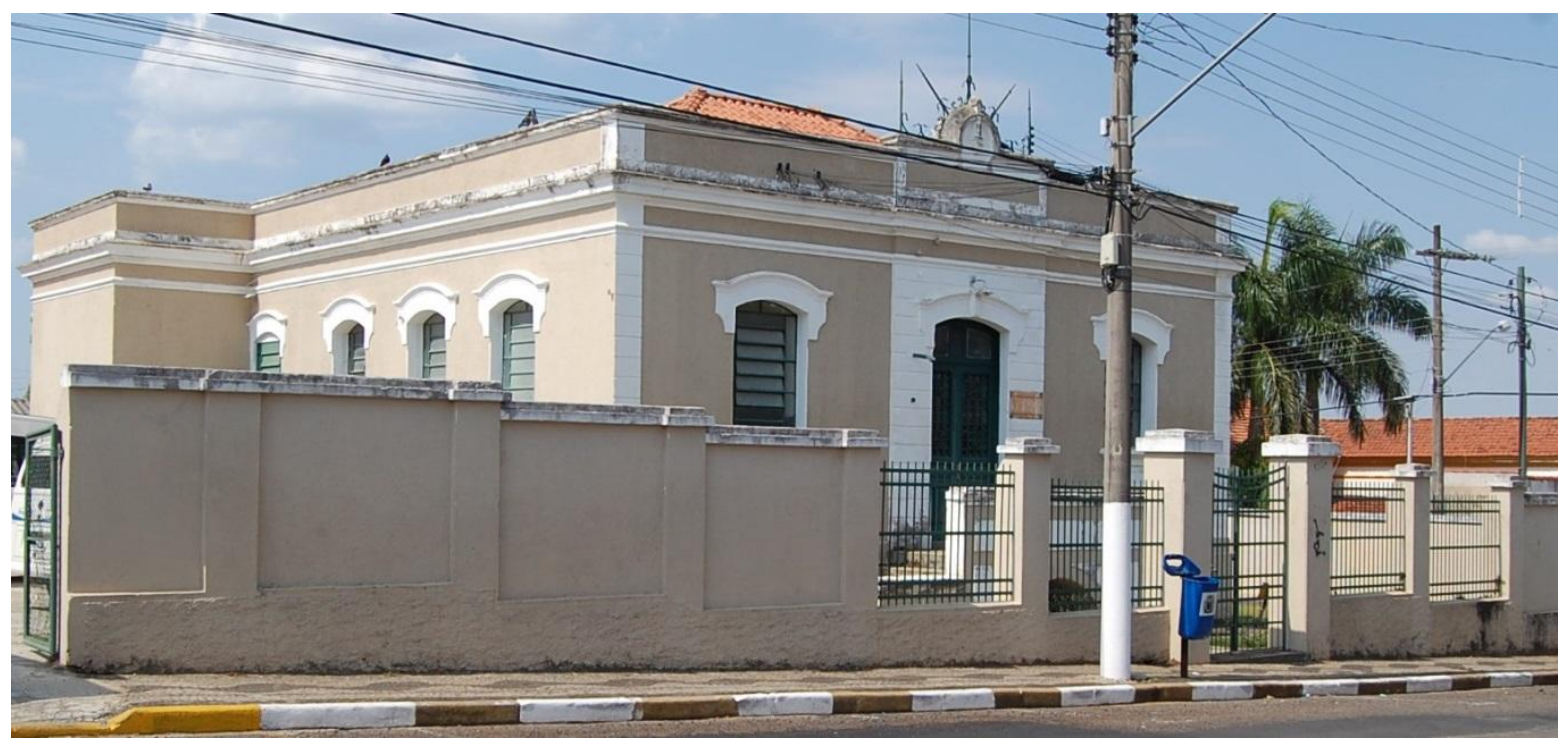

Figura 1. Fotografia da antiga Delegacia de Polícia e Cadeia Pública, Angatuba 31 de maio de 2013. Fonte: a autora.

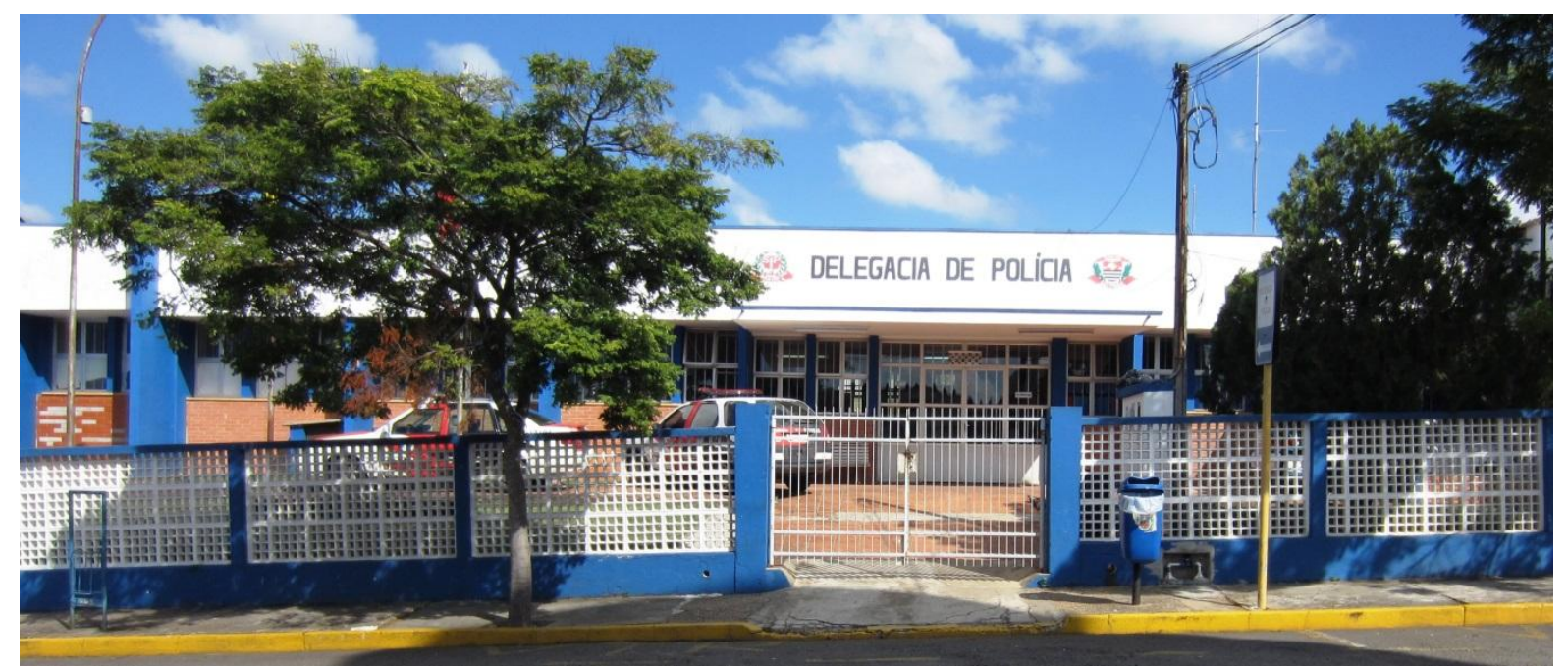

Figura 2. Fotografia da atual Delegacia de Polícia, Angatuba 31 de maio de 2013.

Fonte: a autora.

Segundo DEVORAK (2008), negligência, abandono, de monumentos e sítios históricos, afetam sua integridade, implicam intolerância, que leva do aniquilamento da multiplicidade, que resulta num instrumental deficiente para compreender e se adaptar à própria realidade atual e 
futura, gerando perturbações tanto para o indivíduo quanto para a coletividade. A partir deste raciocínio, é relevante a proposta de um novo uso para o edifício, uma vez que tal uso seja atual e pertinente, e que garanta a sua vitalidade.

A proposta de um novo uso deve, no entanto, ser pertinente às necessidades atuais da cidade, por isso a necessidade de se conhecer a vida cotidiana da população, a história local, suas tradições e manifestações culturais.

A análise dos aspectos culturais de Angatuba possibilitou a constatação de que a cidade é carente de equipamentos culturais para o entretenimento, uma vez que a população perdeu dois dos espaços destinados à este fim, ambos para estabelecimentos particulares. No entanto, na época em que estes locais ainda estavam ativos, havia eventos culturais frequentes em que a população participava assiduamente.

Estes eventos requerem para cada qual um espaço propício para este fim. A apresentação de um teatro requer um ambiente distinto, por exemplo, de uma exposição de arte. Portanto, para que diferentes eventos possam ocorrer em um único lugar, este deve ser flexível, interativo, móvel, de arquitetura transparente, possibilitando aos usuários inventarem suas próprias regras. Se estabelecermos uma forma rígida para determinado uso, para determinada época, a construção logo será obsoleta em desuso, como ocorreu com a antiga delegacia.

“[...] essa inflexão maligna, esse efeito perverso, não há prospectiva que possa se integrar no imaginário tecnológico e filosófico da própria época".(BAUDRILLARD, 1996)

O prédio da Antiga Delegacia de Polícia e Cadeia pública, foi construído em 1920 e é característico do ecletismo, possuindo divisão interna de pequenos cômodos (FIGURA 3), o que dificultaria muito a execução destes eventos culturais no seu interior que necessitam de amplos espaços abertos. Outro obstáculo para esta radical mudança de usos, é o fato de a construção ser uma preexistência, devendo ser considerada como tal. 


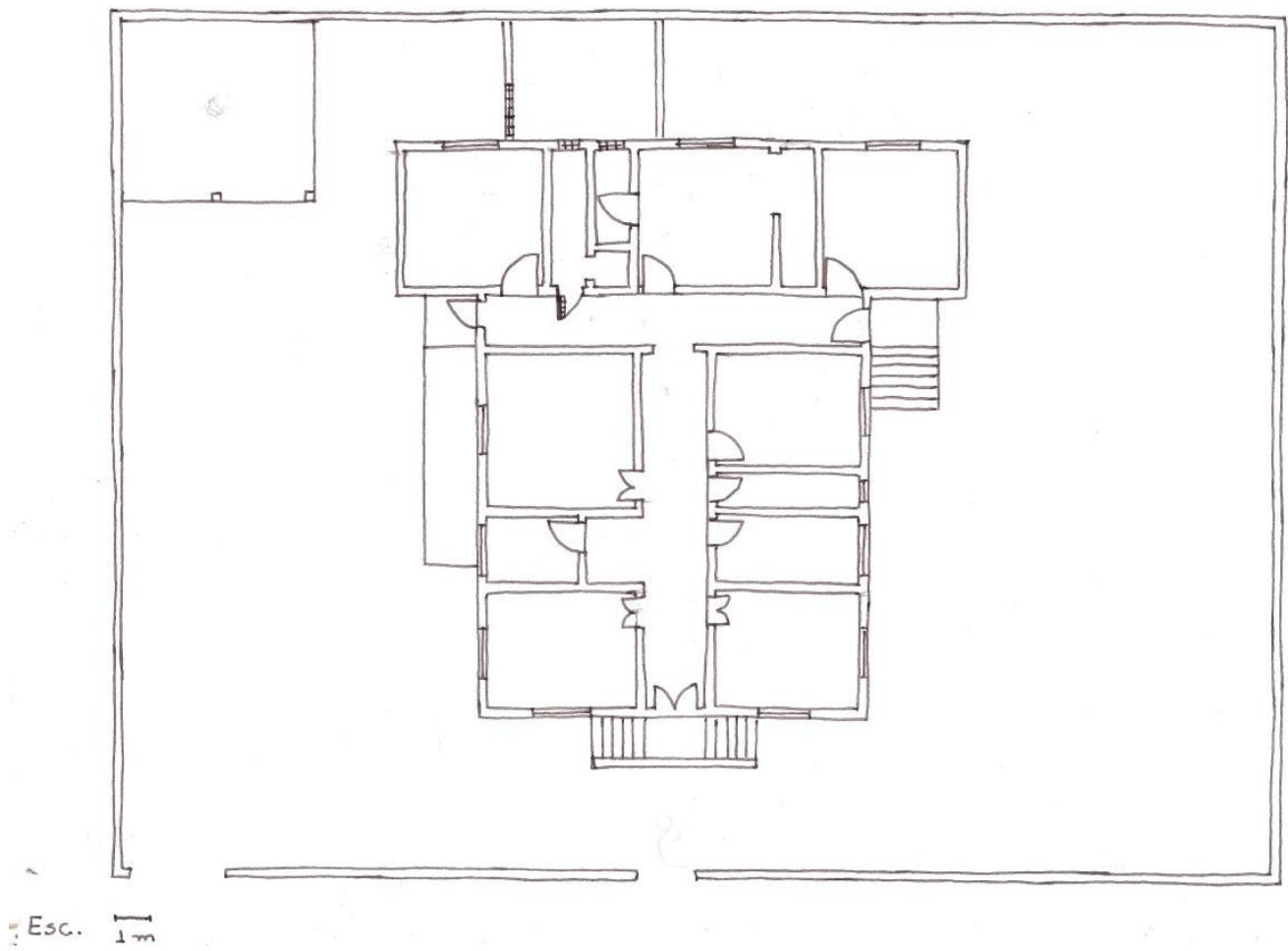

Figura 3. Planta baixa do antigo prédio da Delegacia, 2013.

Fonte: prefeitura de Angatuaba, modificada pela autora.

As paredes internas, apesar de a maioria fazer parte do projeto original, não possuem um valor arquitetônico, e serão suprimidas para dar lugar a um ambiente contínuo, aberto e flexível, no qual possam ser introduzidas e/ou retiradas estruturas de acordo com a ocasião.

\section{DISCUSSÃO}

Muito se tem discutido e publicado, atualmente, sobre a preservação do patrimônio cultural edificado e sobre a possibilidade de reutilização do mesmo para fins necessários às sociedades atuais, o que, a princípio, propicia, para além da mera elevação dos bens arquitetônicos à categoria de patrimônio cultural, um retorno de tais bens ao cotidiano das mais diversas comunidades.

“A reutilização do edifício é a maneira mais eficaz para garantir sua preservação, pois um monumento sem uso se deteriora rapidamente, enquanto aquele mantido em funcionamento pode durar séculos" (Kuhl, 1998). 


\section{CONCLUSÃO}

Angatuba foi perdendo, com o decorrer do tempo, espaços e iniciativas para a promoção de eventos culturais. A população, sem alternativas de entretenimento, muitas vezes recorre ao hedonismo e consumismo, frequentando o shopping e o cinema de Itapetininga, cidade vizinha. Portanto, a reabilitação da antiga delegacia de policia e cadeia pública para a criação de um Espaço Múltiplo com a finalidade de abrigar eventos culturais é apropriado e relevante. A intenção é que a readequação do prédio em um espaço eclético possibilite resgatar os projetos que anteriormente eram realizados, tais quais concurso de conto, recital de poesias, teatros, projeção de filmes e vídeos, exposição de arte, entre outros possivelmente pertinentes.

\section{REFERÊNCIAS}

BAUDRILLARD, Jean. A Violência do Objeto. AU, São Paulo, n 64, p. 69-71, fev/mar 1996.

BRANDI, Cesari. Teoria da Restauração. São Paulo: Ateliê Editorial, 2004.

KUHL, Beatriz Mugayar. Os Recentes Debates Sobre Preservação. In: Arquitetura do Ferro e Arquitetura Ferroviária em São Paulo: reflexões sobre a sua preservação. São Paulo: Ateliê Editorial, 1998. P. 208-220. 